\title{
Effect of Fasting in Ramadan on the level of Chemical Parameters and Percentage of Fatty Acids in the Serum
}

\author{
Raghad Amer Ahmed Al Hialy \\ Mohammed Abd AL-Hadi Jasim \\ Chemistry Department \\ College of Education For Pure Science \\ University of Mosul \\ Rughad.Ammer@yahoo.com \\ M.7186@yahoo.com
}

DOI: $\underline{10.33899 / \text { edusj.2019.162966 }}$

$\begin{array}{cc}\text { Received } & \text { Accepted } \\ 24 / 12 / 2018 & 27 / 02 / 2019\end{array}$

\begin{abstract}
This study included (50) samples of fasting healthy people in Ramadan males and females with ages between (80-19) years and (50) samples of healthy people who are not infected with any apparent disease without fasting males and females were considered a control group of the same categories Age above. In this study, blood samples were collected for healthy people in the case of fasting and control group after fasting period for fasting group (10-15) days and then follow the same people after (20) days and then the serum was separated, where the serum divided into two parts .The biochemical parameters in part one glucose (Glu), total cholesterol (TC), high-density lipoprotein cholesterol (HDL), low-density lipoprotein cholesterol (LDL), very low-density lipoprotein cholesterol (VLDL), triglyceride(TG) and phospholipids was measured by using kits obtained from regional and international suppliers. The measurement of percentage of fatty acids in the three parts (CE, TG, PL) was performed by Capillary Gas Chromatography (CGC). The results showed that there was a significant increase in the percentage and level of saturated fatty acids (SFA), a significant decrease in monounsaturated fatty acids (MUFA) and a significant decrease in polyunsaturated fatty acids (PUFA), in the cholesterol ester (CE) part of serum lipids for the fasting group compared with the control group.Also, the results of this study showed that there was a significant increase in (SFA), a significant decrease in (MUFA), and a significant increase in (PUFA) in triglyceride (TG) part in serum of the fasting group compared to the control group.The results showed that there was a significant increase in (SFA), a significant decrease in (MUFA) and a significant decrease in (PUFA) in phospholipids (PL) part in the serum for the fasting group compared with the control group.
\end{abstract}

Keywords: fasting, fatty acids, cholesterol ester, triglyceride, phospholipids. 
تأثير الصوم في رمضان على مستوى المتغيرات الكيموحياتية والنسبة المئوية للأحماض

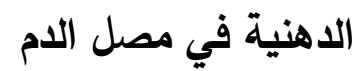

\author{
رغد عامر احمد \\ محمد عبد الهادي جاسم \\ قسم الكيمياء / كلية التربية للعلوم الصرفة

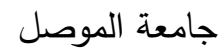

Rughad.Ammer@yahoo.com

M.7186@yahoo.com

DOI: $\underline{10.33899 / \text { edusj.2019.162966 }}$

القبول

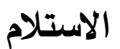

2019 / 02 / 27

2018 / 12 / 24

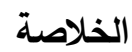

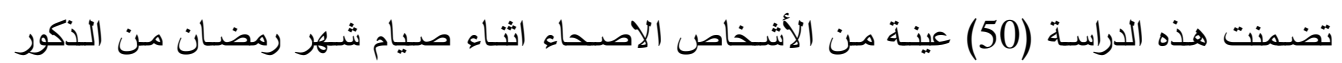

والاناث تتراوح أعمارهم ما بين (19-80) سنة و (50) عينة لأشخاص اصحاء غير مصابين باي مرض ظاهنة الاهري

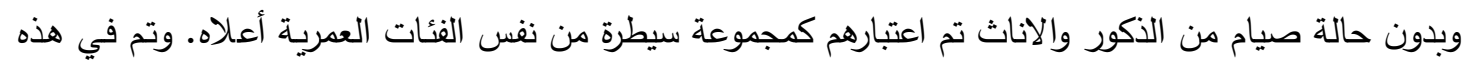

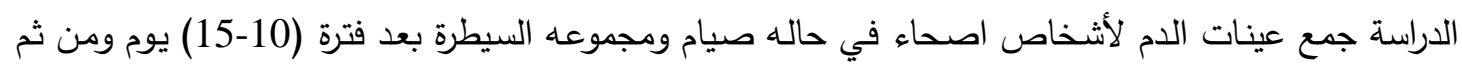
متابعة نفس الاشخاص بعد (20) يوم من الصيام ومن ثم فصل مصل الدم، اذ قسم المصل الى جزئين. وتم قياس المتغيرات الكيموحياتية في الجزء الأول الاتية من مصل الدم الات (الكلوكوز ، الكوليستيرول الكلي، كوليستيرول

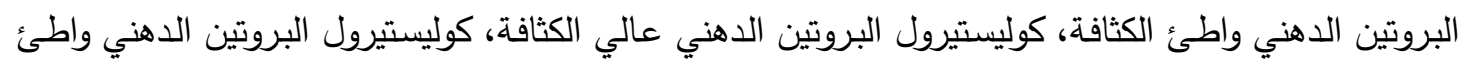

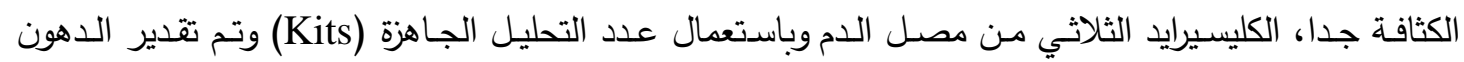

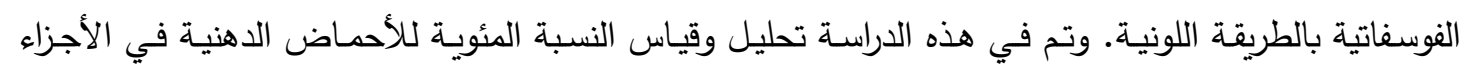

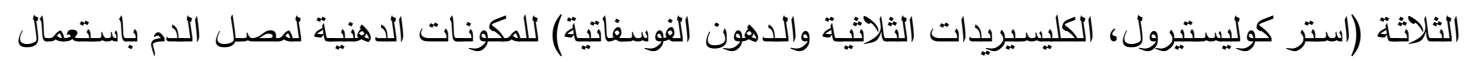
جهاز كروموتوكرافيا الغاز الشعري (Capillary Gas Chromatography) (CGC) و واشارت نتائج هذه

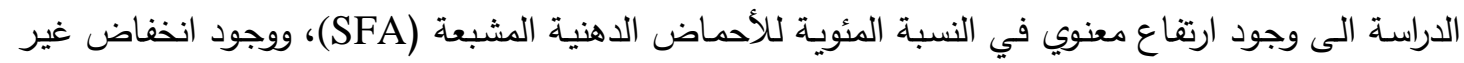

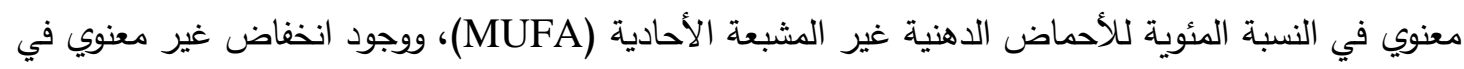

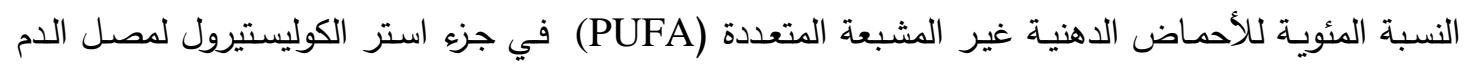

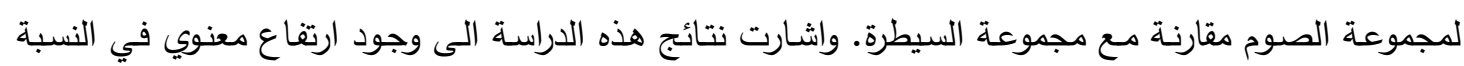

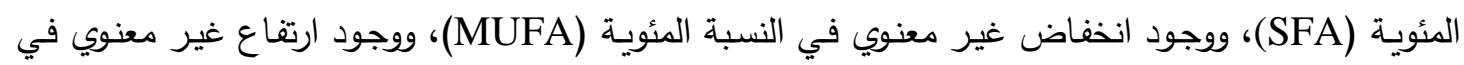
النسبة المئوية (PUFA) في جزء الكليسيرايد الثلاثي لمصل الدم لمجموعة الصوم مقارنة مع مجموعة السيطرة.

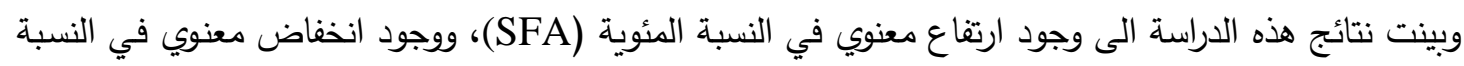

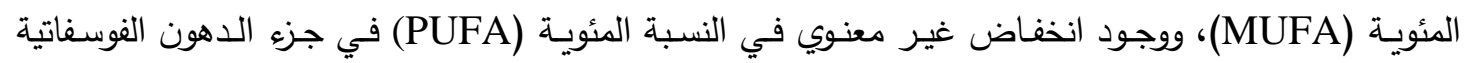

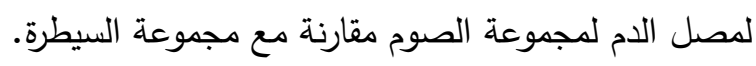

الكلمات المفتاحية: الصوم، الاحماض الدهنية، كوليسترول استر ، الكليسيرايد الثلاثي، دهون فوسفاتية. 
صمدت هذه الدراسـة للتعرف على تأثير الصوم على مستوى المتغيرات الكيموحياتيـة والنسبة المئويـة

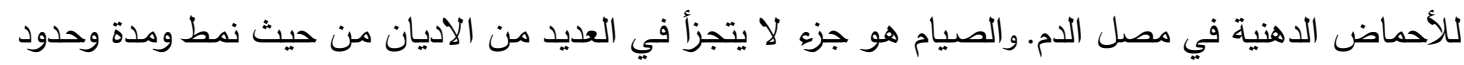

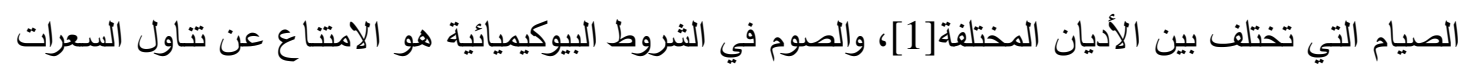

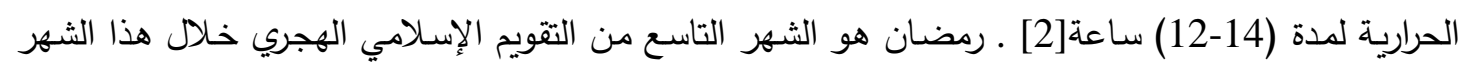

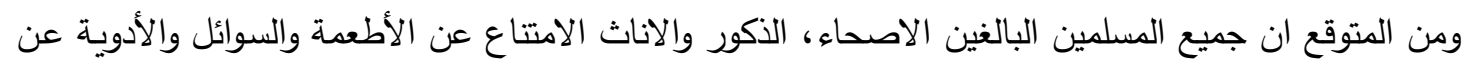
طريق الفم والتدخين من طلوع الفجر الى غروب الثمس وهذا النوع من الصدوم تتاولته دراستتا الذي يستمر (من الن 29 الى 30 يوم)[3]. والصيام يؤثر على العديد من العمليات الايضية في جسم الانسـان وتعود المؤشرات

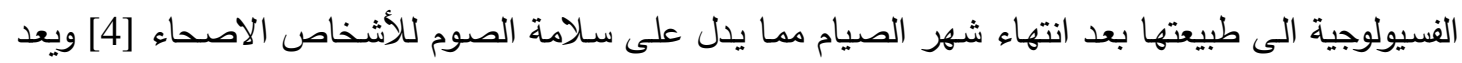

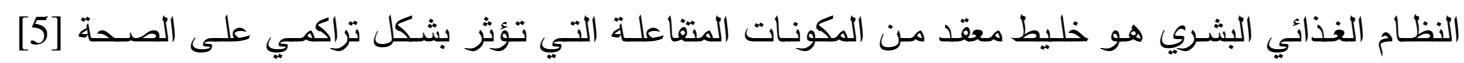
والصيام هو نموذج ممتاز لكيفية تأثير التعديلات الغذائية على ملف الدهون [6] حيث أظهرت الدراسات تغيرات مفيدة في مصل الدم على المتغيرات الكيموحياتيـة من حيث ارتفاع المتغيرات (HDL (ApoA

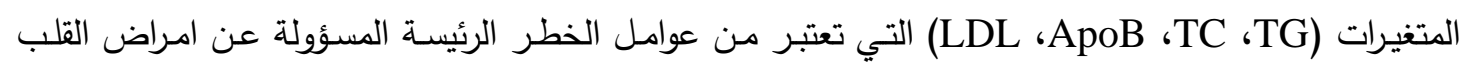

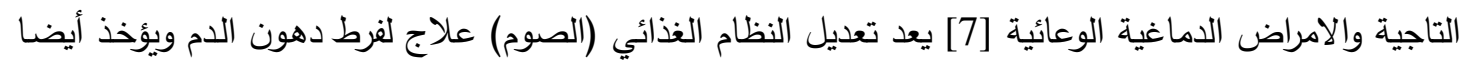

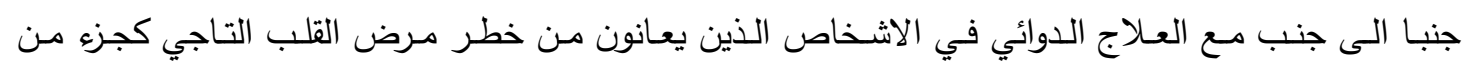

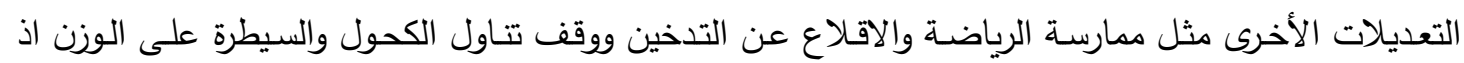
ساعد العلاج الغذائي (الصيام) في انخفاض طفيف في مستويات الدهون لدى عينات الدراسة [8]. وكذلك يؤثر الصوم كذلك على النسب المئوية للاحماض الدهنية في الأجزاء الثلاثة لمصل الدم اذ يكون هذا التأثير إيجابيا وتكون نسبة الاحماض الدهنية بأصنافها المختلفة متوازنة في الأجزاء الثلاثة من مصل الأهل الدم [13].

المواد وطرائق العمل

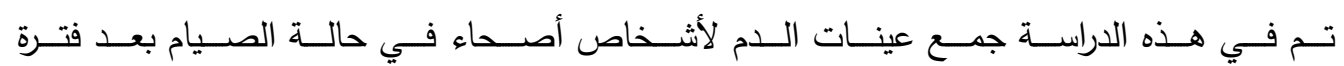
(15-10) يوماً ومن ثم متابعة الأشخاص انفسهم بعد (20) يوماً من الصيام ومجموعة السيطرة حيث تم جمع

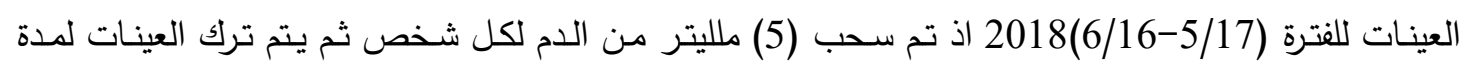

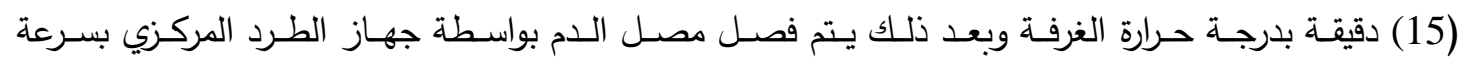
ولمدة (15) دقيقة. يتم بعد ذلك عزل مصل الدم بواسطة ماصسة مايكرويـة ويوضع في أنابيب اختبار ويقسم إلى قسمين:

• (القسم الاول: يتم اجراء القياسات التالية:

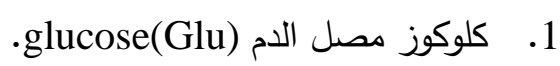

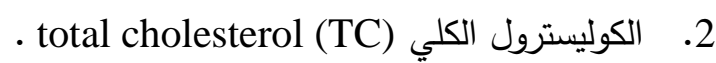

3. كوليسترول البروتين الدهني عالي الكثافة high-density lipoprotein cholesterol(HDL-C) .

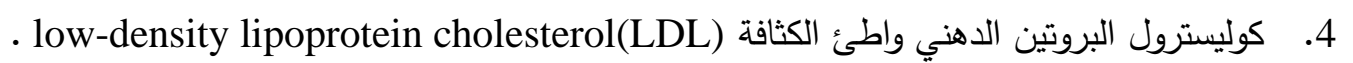

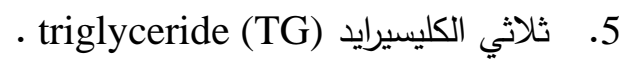
6. phospholipids (PL) الدهون الفوسفاتية الخيرايد 
تأثير الصوم في رمضان على مستوى المتغيرات الكيموحياتية والنسبة المئوية للأحماض الدهنية في مصل الام.

11 كئ الكثاف دهني واط لـروتين الـ ــترول البـــــــ 7. كوليس very low-density lipoprotein cholesterol (VLDL-C)

• القسم الثاني: يحفظ في التجميد بدرجة (-18) مْ لحين بدء التحليل للأحماض الدهنية.

تحليل وقياس نسبة الاحماض الدهنية لمصل الدم: تم قياس النسبة المئوية للأحماض الدهنية للأجزاء الثلاثة في مصل الأليه الدام (استر الكوليسترول، الدهون الفوسفاتية والكليسيرايد الثلاثي) بعد عملية فصل كل جزء من الأجزاء الثلاثة باستعمال تقنية كروموتوكرافيا الطبقة

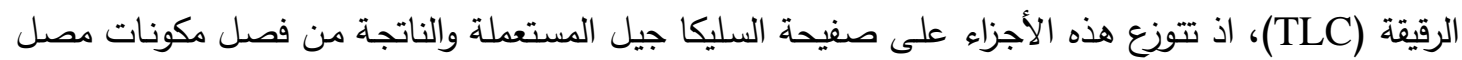

الدم باستعمال نظام مذيب يتكون من (الهكسان/ الايثر/ حامض الفوريك) بنسب (V/V/V) (2:20:80).

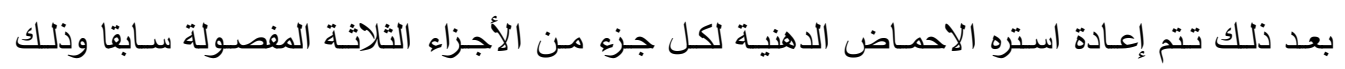
باستعمال (BF3/Methanol) بنسبة (16\%) [9]، ومن ثم اجراء تشخيص وتحليل النسبة المئويـة للأحماض الدهنية لكل جزء باستعمال نماذج قياسية.

تقدير النسبة المئوية للأحماض الدهنية: تم تقدير نسبة الاحماض الدهنية في مصل الدم للمكونات الثلاثة الأنفة الذكر وذلك بوساطة حقن (1)

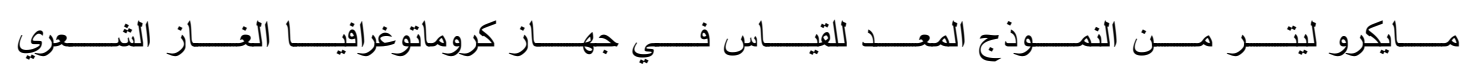
.[10](CGC) (capillary gas chromatography) اذ يوضـح الثـكل (1) الرســـ النـاتج مـن تحليـل وقيـاس نسـبة (23) حامضــا دهنيـا قياسـي باسـتعمال جهـاز كروموتوكرافيا الغاز الشعري (CGC).

الجدول (1): يوضح أسماء وزمن احتباس والنسبة المئوية ل (23) حامض دهني قياسي

\begin{tabular}{|c|c|c|c|}
\hline النسبة المئوية (\%) & زمن الاحتباس (دقيقة) & الرمز & $\begin{array}{c}\text { الاحماض الدهنية القياسية } \\
\text { (methyl ester) }\end{array}$ \\
\hline 0.09 & 2.28 & C $4: 0$ & البيوتريك \\
\hline 0.14 & 3.62 & C 6:0 & الكابرويك \\
\hline 0.15 & 6.47 & C 11:0 & الانديكانويك \\
\hline 0.172 & 10.81 & C 12:0 & الليوريك \\
\hline 0.084 & 13.23 & C 14:0 & الميريستك \\
\hline 0.18 & 15.71 & C $15: 0$ & البنتاديكانويك \\
\hline 0.086 & 18.12 & C 16:0 & البالمتيك \\
\hline 0.17 & 20.51 & C 18:0 & الستيريك \\
\hline 0.095 & $21: 25$ & C 18:1trans & الايلايديك \\
\hline 0.036 & $22: 79$ & C 18:1 cis & الاوليك \\
\hline 0.048 & $23: 46$ & C $18: 2$ & اللينوليك \\
\hline
\end{tabular}


محمد عبد الهادي جاسم \& رغد عامر احمد

\begin{tabular}{|c|c|c|c|}
\hline النسبة المئوية (\%) & زمن الاحتباس (دقيقة) & 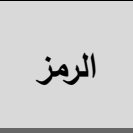 & الاحماض الدهنية القياسية \\
\hline 0.068 & $27: 47$ & C $18: 3$ & اللينولينلك \\
\hline 0.363 & $25: 22$ & C 20:0 & الاراكيديك \\
\hline 0.338 & 29.73 & C 21:0 & الهينيكوسانويك \\
\hline 0.01 & 30.33 & C 22:0 & البيهينيك \\
\hline 0.039 & 31.48 & C $22: 1$ & الاورسيك \\
\hline 0.178 & 33.67 & C 20:4 & الاراكيدونيك \\
\hline 0.03 & 34.34 & C 23:0 & التريكوسيليك \\
\hline 0.024 & 35.70 & C $22: 2$ & سس،الدكوسانويك \\
\hline 0.323 & 37.32 & C 24:0 & الليغنوسيريك \\
\hline 0.031 & 38.74 & C $20: 5$ & الايكوسابنتانويك \\
\hline 0.015 & 39.23 & C $24: 1$ & النيرفونيك \\
\hline 0.099 & 40.73 & C 22:6 & الدوكوسا هيكسا ينويك \\
\hline
\end{tabular}

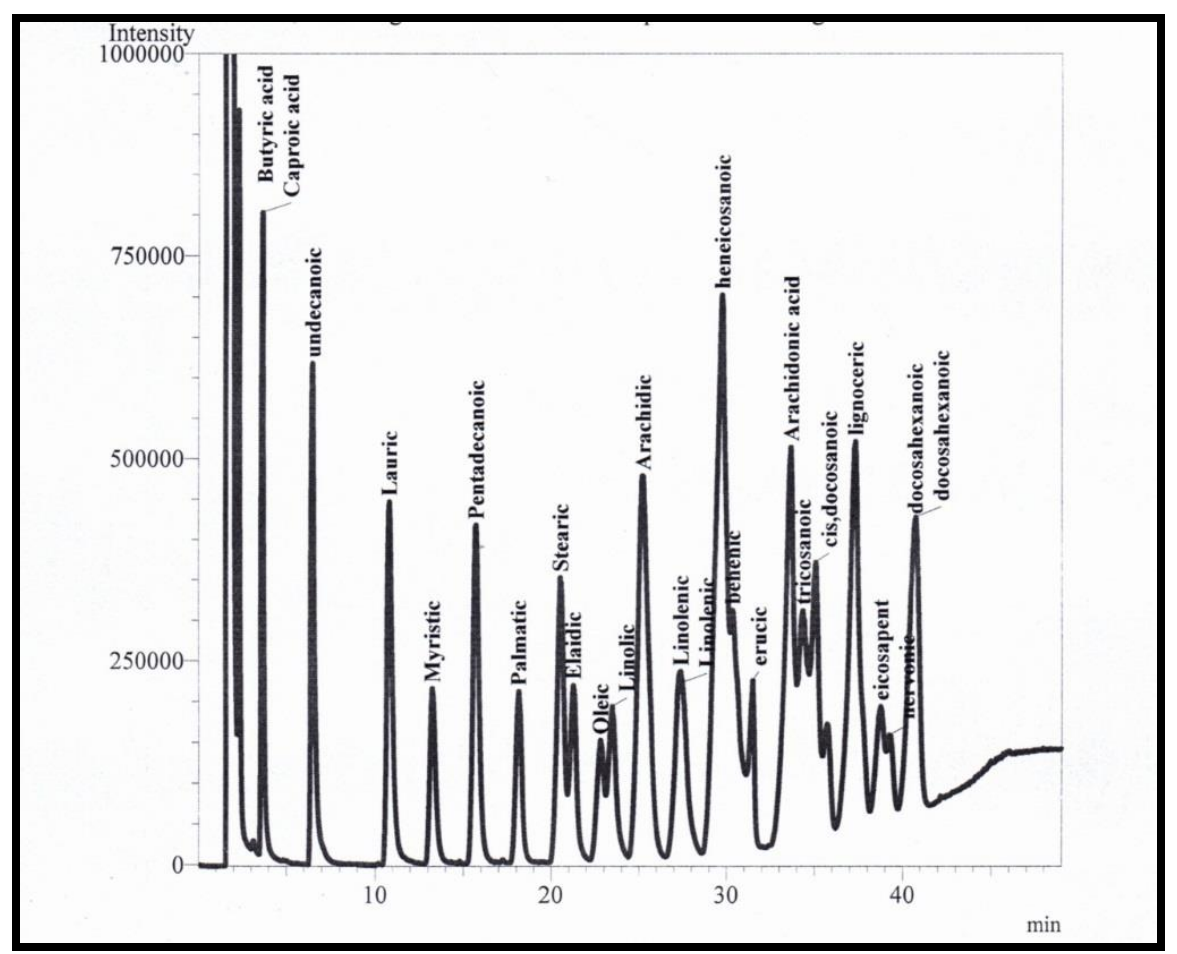

الثكل (1): مخطط لنموذج قياسي يتكون من (23) حامض دهني

التحليل الاحصائي:

تم تحليل نتائج مستويات المتغيرات الكيموحياتيـة (الكلوكوز ، الكوليسترول الكلي، كوليسترول البروتين

الدهني واطئ الكثافة، كوليسترول البروتين الدهني عالي الكثافة، كوليسترول البروتين الدهني واطئ الكثافة جدا،

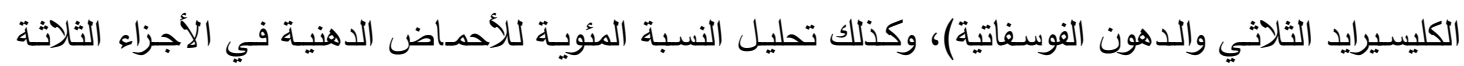
المفصولة من دهون مصل الدم باستخدام اختبار (t-test) للمجاميع المتساوية في العدد، والمجاميع المختلفة 
وذلك لمقارنـة نتائج الأشـاص في حالـة الصسوم مـع مجموعـة السيطرة بشكل عـام إذ كان مستوى الاحتماليـة المقبول هو (111)

النتائج والمناقشة:

اظهرت النتائج لهذه الدراسة انخفاض معنوي لتركيز الكلوكوز في مصل الدم لمجموعة الصوم مقارنة مع مجموعة السيطرة كما موضح في الجدول (2) وقد يعزى السبب في ذلك الى انخفاض كمية السعرات الحرارية المتاولة خلال شهر رمضان مقارنة مع الاشهر الاخرى وكذلك طبيعة الجهد العضلي والنوم خلال شهر الصيام

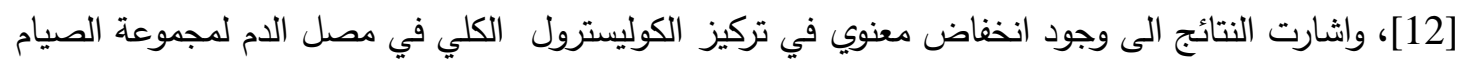

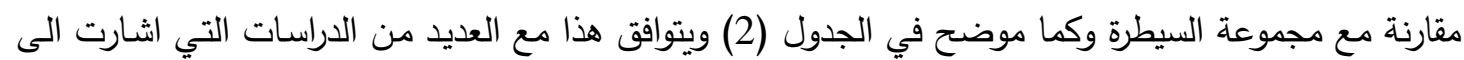

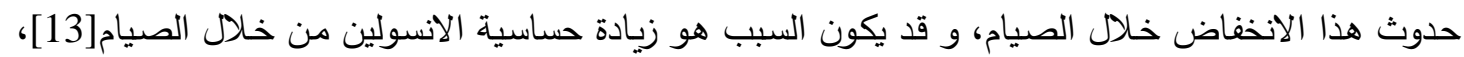

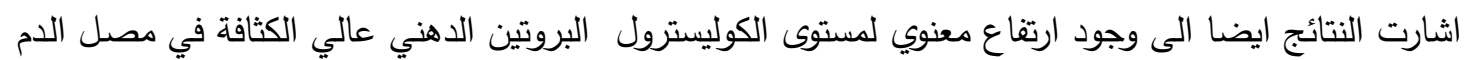

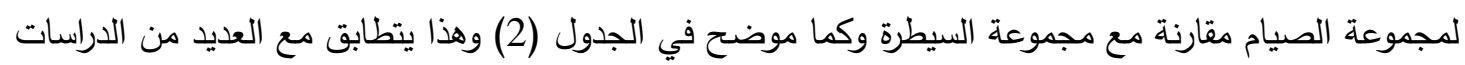

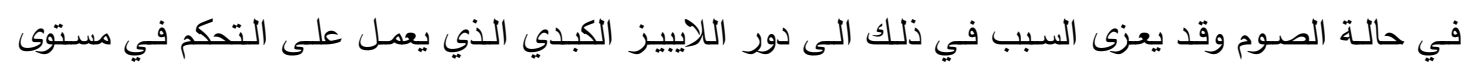

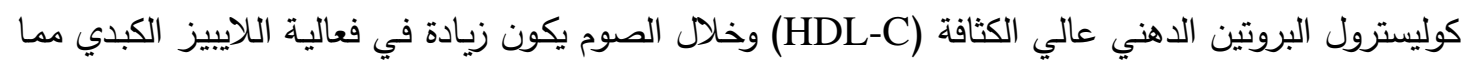
يؤدي الى ارتفاع مستوى هذا النوع من الكوليسترول خلال فترة الصيام وانخفاض مستوى الكوليسترول الكلي [4,6]، اشـارت نتائج هذه الدراسـة الى وجود انخفاض معنوي في مستوى هوتى كوليسترول البروتين الدهني واطئ

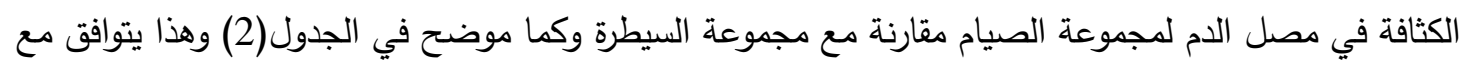

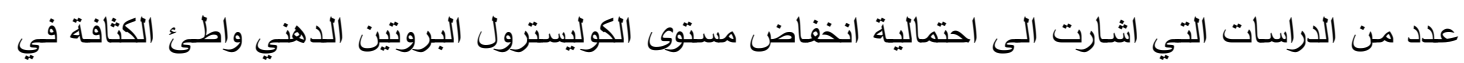
مصل الدم خلال فترة الصيام وقد يعزى السبب في ذلك الى حدوث انخفاض في حساسية مستقبلات الاستايل CoA

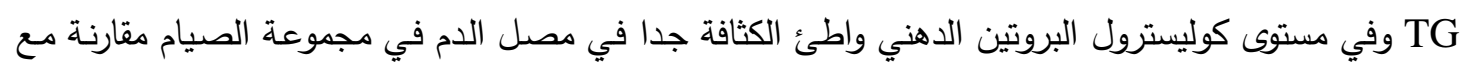
مجموعة السيطرة وكما موضح بالجدول (2) يمكن ان يعود السبب في ذلك الى طبيعة الغذاء المتناول خلال فترة

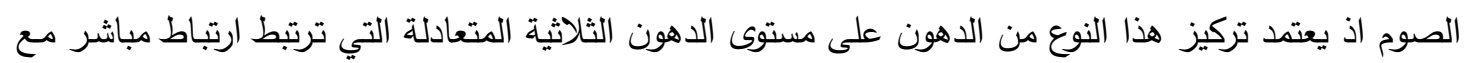

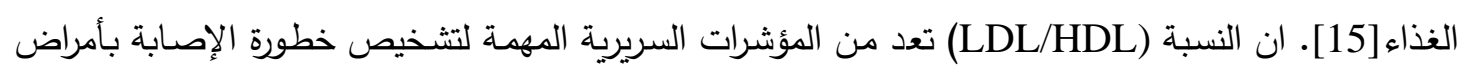
القلب الوعائية [16] ان الارتفاع او الانخفاض في هذه النسبة حيث مؤشرا على مدى سير العمليات الايضية

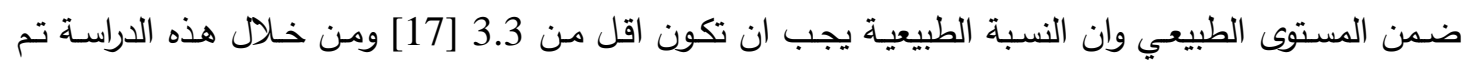
ملاحظة ان هذه النسبة تتخفض في مجموعة الصوم مقارنة مع مجموعة السيطرة كما موضح في الجدول (2)،

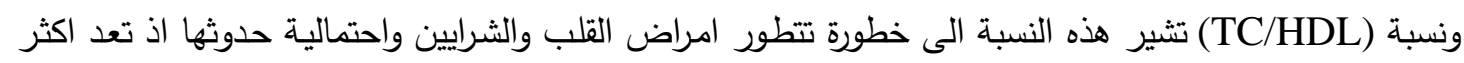

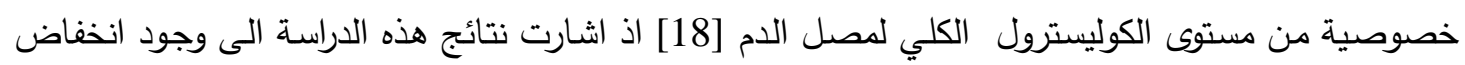
معنوي في هذه النسبة لمجموعه الصيام مقارنة مع مجموعة السيطرة كما موضح في الجدول (2)، واما النسبة

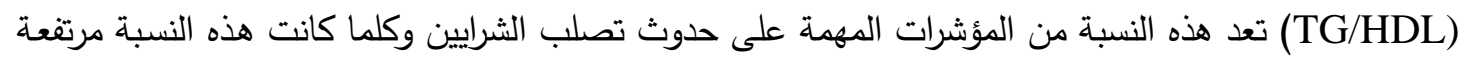

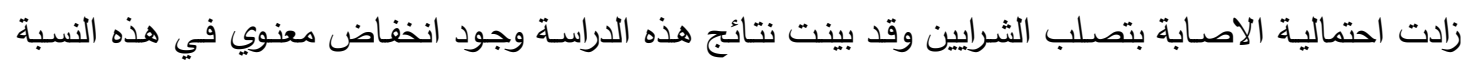

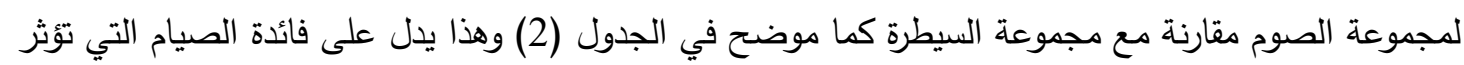
على مستوى الانسولين في مصل الدم والذي يؤثر بدوره على ايض الدهون الثلاثية والكوليسترول عالي الكثافة والكوليسترول الكلي بشكل كبير [19]. واشارت نتائج هذه الدراسـة الى وجود انخفاض لـونين معنوي لمستوى الدهون 
الفوسفاتية في مصل الدم لمجموعة الصيام مقارنة مع مجموعة السيطرة اذ ان السبب يعود الى عدة عوامل اهمها دور انزيم اللايبيز الكبدي اذ يكون فعال خلال فترة الصوم مما يؤدي الى زيادة تحلل الدهون بشكل عام والدهون الفوسفاتية بشكل خاص [20].

جدول (2): المتغيرات الكيموحياتية لمجموعة السيطرة ومجموعة الصيام.

\begin{tabular}{|c|c|c|c|}
\hline \multirow{2}{*}{ p* قيمة p } & صيام عام & مجموعه السيطرة & المتغيرات الكيموحيوية \\
\hline & 50 & 50 & العدد \\
\hline $0.001>$ & $0.78 \pm 4.13$ & $0.94 \pm 5.04$ & الكلوكوز (ملمول/ لتز ) \\
\hline 0.093 & $0.97 \pm 4.60$ & $0.81 \pm 4.91$ & الكوليسترول الكلي (TC)(ملمول/لتر) \\
\hline 0.059 & $0.43 \pm 1.43$ & $0.42 \pm 1.27$ & كوليسترول البروتين الدهني عالي الكثافة (HDL-C) \\
\hline 0.001 & $0.85 \pm 3.13$ & $0.70 \pm 3.68$ & كوليسترول البروتين الدهني واطئ الكثافة (LDL-C) \\
\hline 0.009 & $0.14 \pm 0.44$ & $0.30 \pm 0.58$ & كوليسترول البروتين الدهني واطئ الكثافة جدا (VLDL-C) \\
\hline 0.004 & $0.53 \pm 1.044$ & $0.71 \pm 1.40$ & ثلاثي الكليسيرايد (TG) (ملمول/ لتر) \\
\hline 0.262 & $1.12 \pm 3.55$ & $1.66 \pm 3.86$ & نسبة Cholesterol/HDL-C \\
\hline 0.334 & $1.00 \pm 2.51$ & $1.02 \pm 2.89$ & LDL-C/HDL-C نسبة \\
\hline 0.051 & $0.46 \pm 0.79$ & $0.62 \pm 1.05$ & نسبة Triglyceride/HDL-C \\
\hline 0.017 & $2.97 \pm 80.3$ & $34.3 \pm 126$ & الدهون الفوسفاتية (PL) (ملغم/100مل) \\
\hline
\end{tabular}

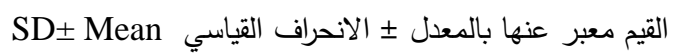

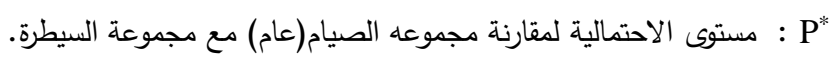

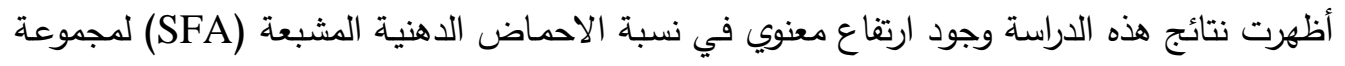

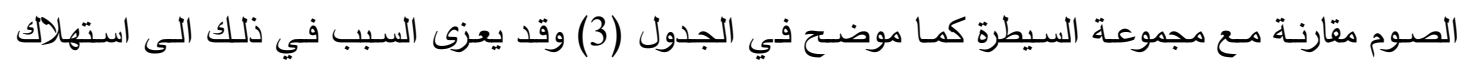

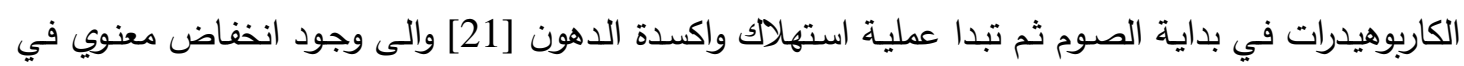

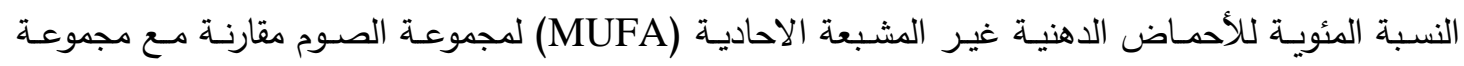
السيطرة كما موضح في الجدول (3) وقد يعزى السبب في ذلك الى تأثير الصوم على عمليات اكسدة الدهون

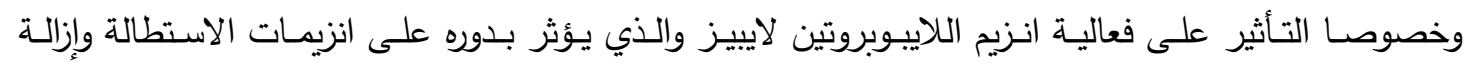

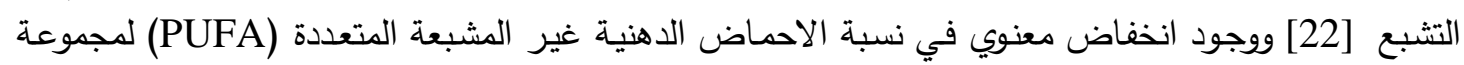

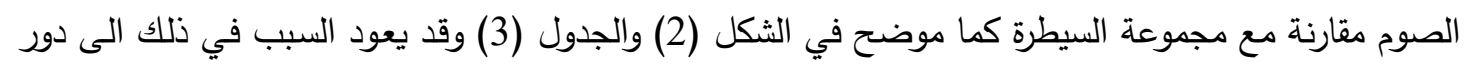

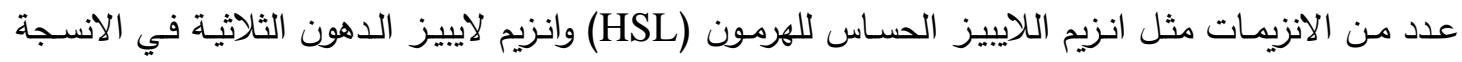

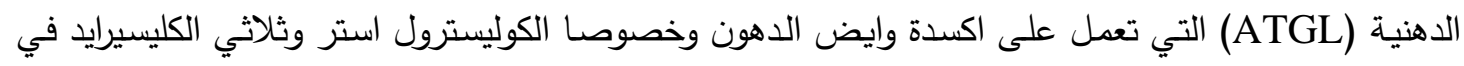

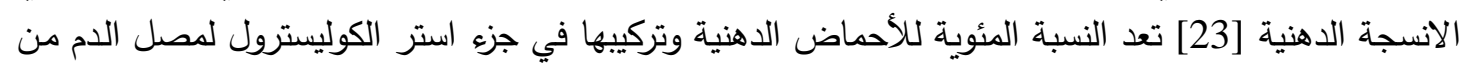

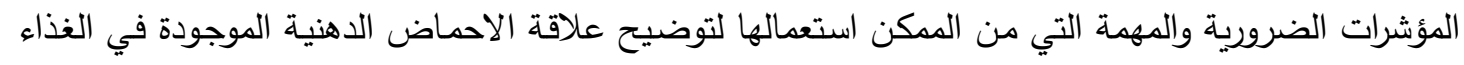

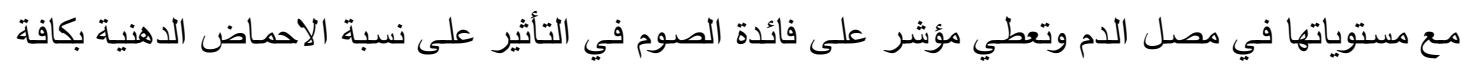
أنواعها في هذا الجزء من مصل الدم فئ [24].

النسبة المئوية للأحماض الدهنية في جزء الكليسيرايد الثلاثي لمصل الدم 
اشارت نتائج هذه الدراسة الى وجود ارتفاع معنوي في الاحماض الدهنية المشبعة (SFA) لمجموعة الدية الصوم مقارنة مع مجموعة السيطرة كما موضح في الجدول(4) وقد يعزى السبب في ذلك الى حساسية الانسولين

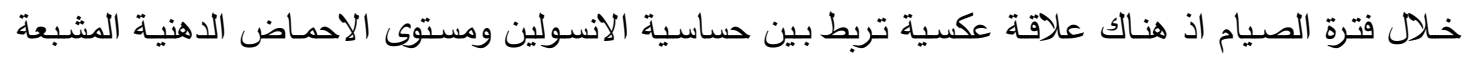
وبذلك تزداد (25FA) واللى وجود ارتفاع غير معنوي في مستوى الاحماض الدهنية غير مشبعة الأحادية

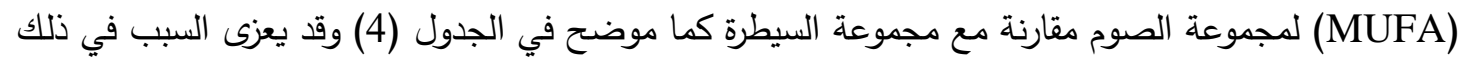

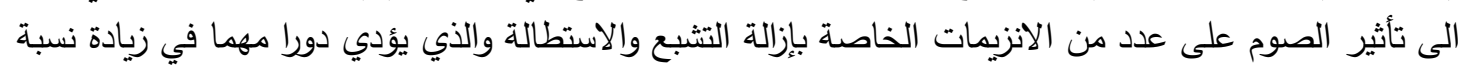

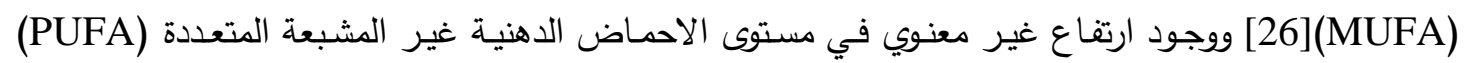

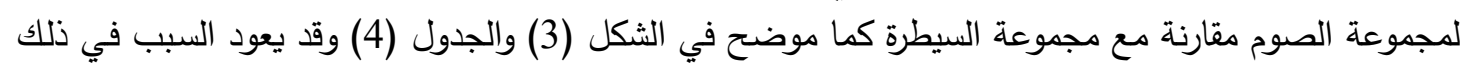

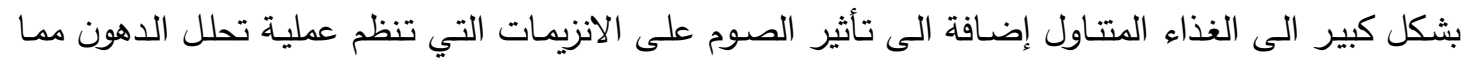

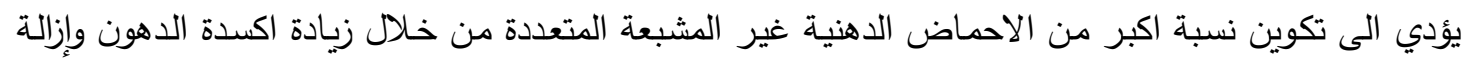

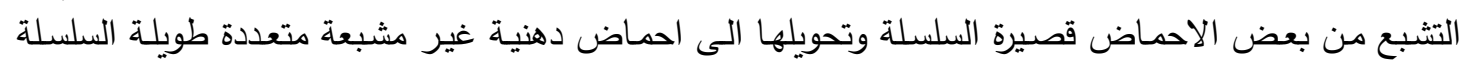

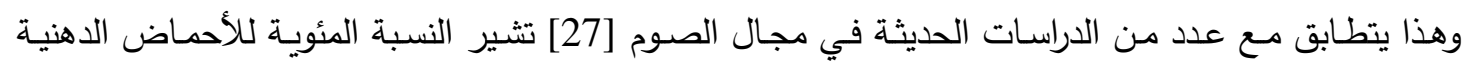
وتركيبها في جزء الكليسيرايد الثلاثي لمصل الدم بشكل عام الى كمية الاحماض الدهنية المتواجدة ضمن الغذاء الثياء

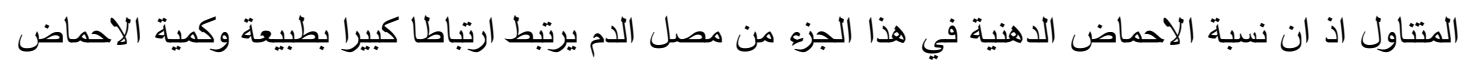
الدهنية المتواجدة في الغذاء المتناول خلال فترة الصوم (الإفطار والسحور ) [28].

النسبة المئوية للأحماض الدهنية في جزء الدهون الفوسفاتية لمصل الدم

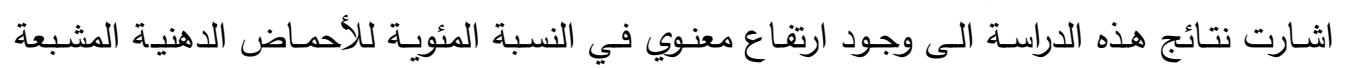

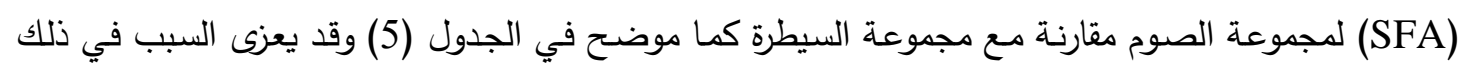

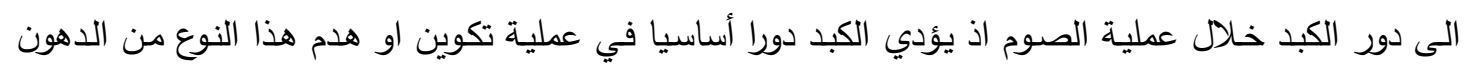

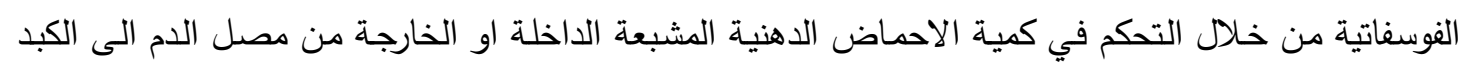
مما يؤثر على النسبة المئوية لهذا النوع من الاحماض اذ ان عملية هدم الدهون تزداد خلال فترة الصيام ويقوم الكبد بدور رئيس في هذه العملية [23] والى وجود انخفاض معنوي في مستوى الاحماض الدهنية غير المشبعة

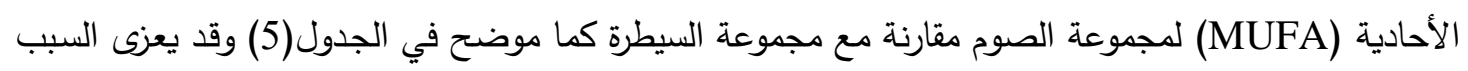

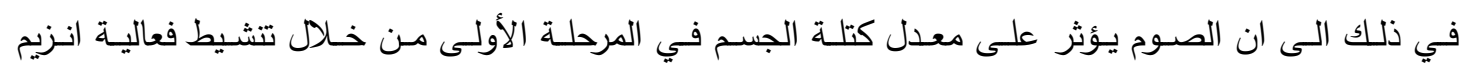

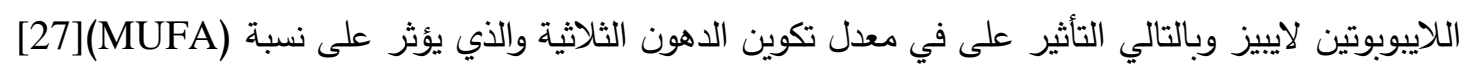

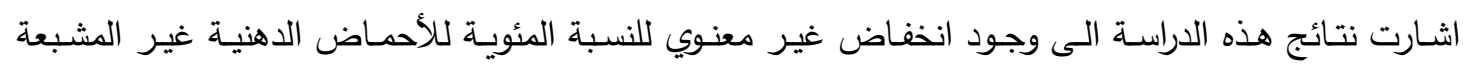

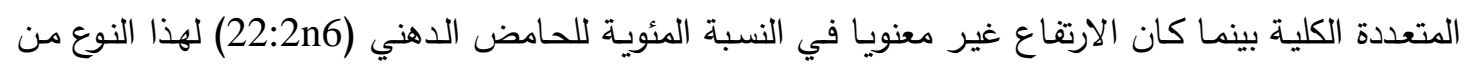
الاحماض الدهنية في هذا الجزء من مصل الدم لمجموعة الصوم مقارنة مع مجموعة السيطرة كما موضتح في لئي

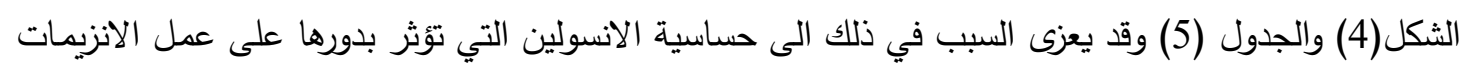

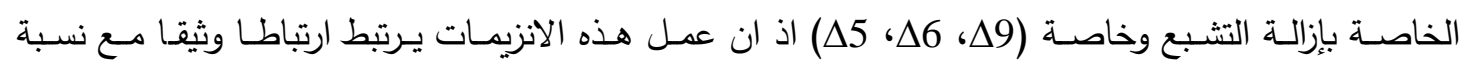

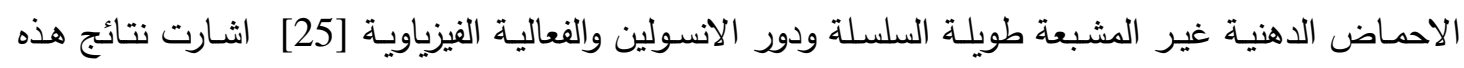

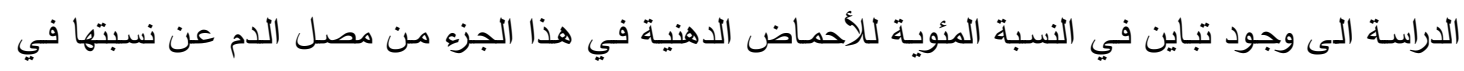

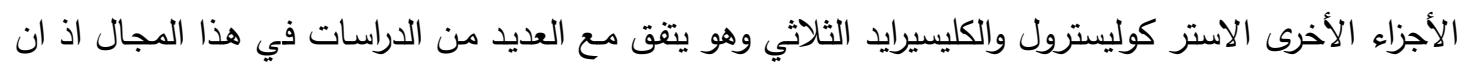

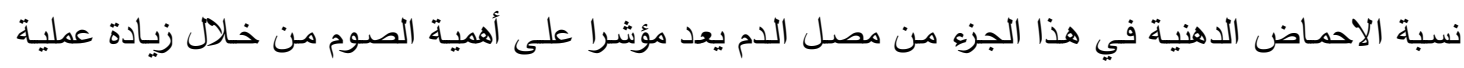

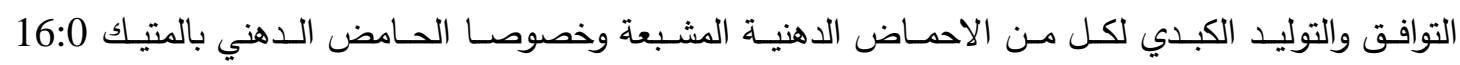
والاحماض الدهنية غير المشبعة المتعددة نوع n:3 اذ يعد الدهون الفوسفاتية من النواقل الجيدة لإعادة تدوير 
الحامض الدهني (DHA) لإعادة تكوين الأنواع المختلفة من البروتينات الدهنية وهو يعزز صحة الجسم من خلال إعادة توزيع وانتقال الاحماض الدهنية بين الأجزاء المختلفة من مصل الدام الدين [23].

جدول (3): النسبة المئوية للأحماض الدهنية في جزء الدهون أستر الكوليسترول لمصل الام

\begin{tabular}{|c|c|c|c|}
\hline صيام عام & نماذج السيطرة & \multirow{3}{*}{ الأحماض الدهنية } & \\
\hline \multicolumn{2}{|c|}{ العدد } & & \\
\hline 7 & 7 & & \\
\hline $1.49 \pm 4.40$ & $0.16 \pm 5.22$ & $6: 0$ & \multirow{13}{*}{$\sqrt{\omega}$} \\
\hline $1.70 \pm 4.25$ & $0.16 \pm 1.95$ & 11:0 & \\
\hline $1.36 \pm 4.84$ & $0.18 \pm 2.35$ & $12: 0$ & \\
\hline $1.33 \pm 3.7$ & $0.18 \pm 2.55$ & $14: 0$ & \\
\hline $1.84 \pm 4.44$ & $0.14 \pm 2.27$ & $15: 0$ & \\
\hline $3.89 \pm 8.78$ & $0.19 \pm 2.35$ & $16: 0$ & \\
\hline $0.33 \pm 2.42$ & $0.11 \pm 2.16$ & $18: 0$ & \\
\hline $0.52 \pm 2.13$ & $0.10 \pm 2.74$ & $20: 0$ & \\
\hline $1.18 \pm 4.08$ & $0.12 \pm 5.85$ & $21: 0$ & \\
\hline $0.47 \pm 2.49$ & $0.01 \pm 1.86$ & $22: 0$ & \\
\hline $0.88 \pm 2.31$ & $0.02 \pm 2.51$ & $23: 0$ & \\
\hline $0.49 \pm 1.99$ & $0.23 \pm 2.66$ & $24: 0$ & \\
\hline $15.48 \pm 45.83$ & $1.6 \pm 34.47$ & المجموع الكلي (Total) & \\
\hline $0.19 \pm 3.76$ & $0.12 \pm 5.00$ & 18:1trans & \multirow{5}{*}{ 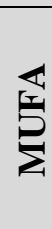 } \\
\hline $0.46 \pm 1.58$ & $0.21 \pm 2.55$ & 18:1cis & \\
\hline $0.01 \pm 0.61$ & $0.28 \pm 2.12$ & $22: 1$ & \\
\hline $0.67 \pm 2.81$ & $0.17 \pm 2.32$ & $24: 1$ & \\
\hline $1.33 \pm 8.76$ & $0.78 \pm 11.99$ & المجموع الكلي (Total) & \\
\hline $0.45 \pm 2.51$ & $0.17 \pm 2.51$ & $18: 2 \mathrm{n} 6$ & \multirow{6}{*}{$\underset{2}{\mathbb{2}}$} \\
\hline $0.45 \pm 2.15$ & $0.28 \pm 2.50$ & $18: 3 \mathrm{n} 6$ & \\
\hline $0.34 \pm 1.92$ & $0.21 \pm 2.91$ & $20: 4 \mathrm{n} 6$ & \\
\hline $1.42 \pm 3.03$ & $0.28 \pm 2.06$ & $22: 2 \mathrm{n} 6$ & \\
\hline $0.33 \pm 2.24$ & $0.19 \pm 2.59$ & $20: 5 \mathrm{n} 3$ & \\
\hline $2.99 \pm 11.85$ & $1.13 \pm 12.57$ & المجموع الكلي (Total) & \\
\hline
\end{tabular}

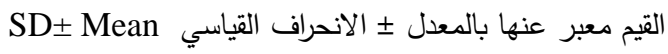

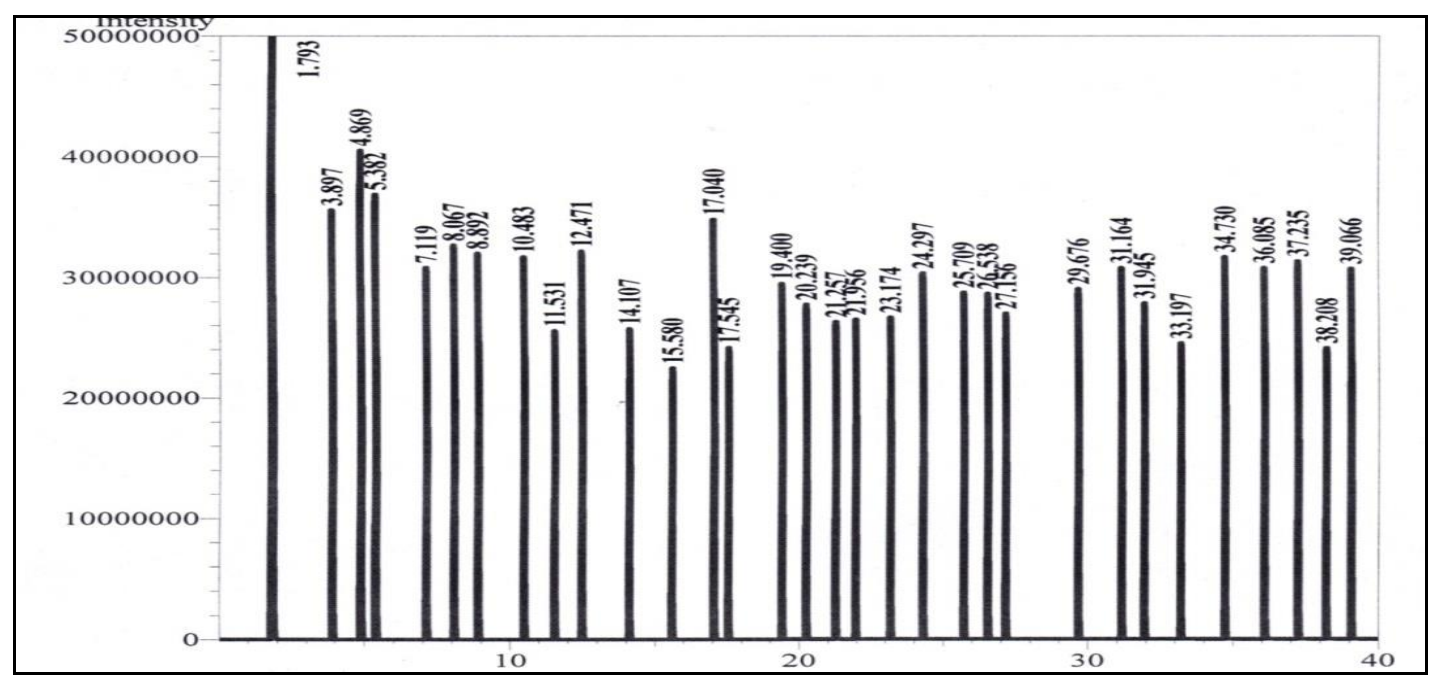

الثكل (2): الأحماض الدهنية في جزء أستر كوليسترول

جدول (4): النسبة المئوية للأحماض الدهنية في جزء الأكليسيرايد الثلاثي لمصل الدام 
تأثير الصوم في رمضان على مستوى المتغيرات الكيموحياتية والنسبة المئوية للأحماض الدهنية في مصل الام.

\begin{tabular}{|c|c|c|c|}
\hline صيام عام & نماذج السيطرة & \multirow{3}{*}{ الأحماض الدهنية } & \\
\hline \multicolumn{2}{|c|}{ العدد } & & \\
\hline 7 & 7 & & \\
\hline $1.52 \pm 4.66$ & $0.19 \pm 1.08$ & $6: 0$ & \multirow{13}{*}{$\sqrt{\infty}$} \\
\hline $1.79 \pm 4.45$ & $0.17 \pm 2.0$ & 11:0 & \\
\hline $1.55 \pm 4.26$ & $0.14 \pm 2.19$ & $12: 0$ & \\
\hline $1.42 \pm 3.53$ & $0.14 \pm 2.39$ & 14:0 & \\
\hline $2.30 \pm 3.78$ & $0.16 \pm 2.32$ & 15:0 & \\
\hline $2.84 \pm 7.05$ & $0.17 \pm 2.12$ & $16: 0$ & \\
\hline $0.45 \pm 2.23$ & $0.23 \pm 2.20$ & $18: 0$ & \\
\hline $0.69 \pm 2.43$ & $0.19 \pm 2.78$ & $20: 0$ & \\
\hline $1.80 \pm 3.40$ & $0.24 \pm 4.42$ & 21:0 & \\
\hline $0.83 \pm 2.56$ & $0.17 \pm 1.89$ & $22: 0$ & \\
\hline $1.21 \pm 3.33$ & $0.32 \pm 2.55$ & $23: 0$ & \\
\hline $1.42 \pm 3.99$ & $0.23 \pm 2.7$ & $24: 0$ & \\
\hline $17.82 \pm 45.67$ & $2.35 \pm 28.64$ & المجموع الكلي (Total) & \\
\hline $0.85 \pm 2.20$ & $0.27 \pm 2.61$ & 18:1trans & \multirow{5}{*}{$\sum_{\Sigma}^{\mathbb{s}}$} \\
\hline $0.50 \pm 1.57$ & $0.14 \pm 2.60$ & 18:1cis & \\
\hline $0.81 \pm 2.08$ & $0.36 \pm 1.23$ & $22: 1$ & \\
\hline $1.13 \pm 3.21$ & $0.12 \pm 2.43$ & $24: 1$ & \\
\hline $3.29 \pm 9.06$ & $0.89 \pm 8.87$ & المجموع الكلي (Total) & \\
\hline $0.24 \pm 2.16$ & $0.17 \pm 2.58$ & $18: 2 \mathrm{n} 6$ & \multirow{6}{*}{ 造 } \\
\hline $0.22 \pm 2.09$ & $0.23 \pm 2.54$ & $18: 3 \mathrm{n} 6$ & \\
\hline $0.24 \pm 1.82$ & $0.26 \pm 2.70$ & 20:4 n6 & \\
\hline $1.57 \pm 3.26$ & $0.34 \pm 2.09$ & $22: 2 \mathrm{n} 6$ & \\
\hline $1.57 \pm 3.47$ & $0.24 \pm 2.63$ & $20: 5 \mathrm{n} 3$ & \\
\hline $3.84 \pm 12.8$ & $1.24 \pm 12.54$ & المجموع الكلي (Total) & \\
\hline
\end{tabular}

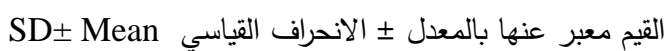

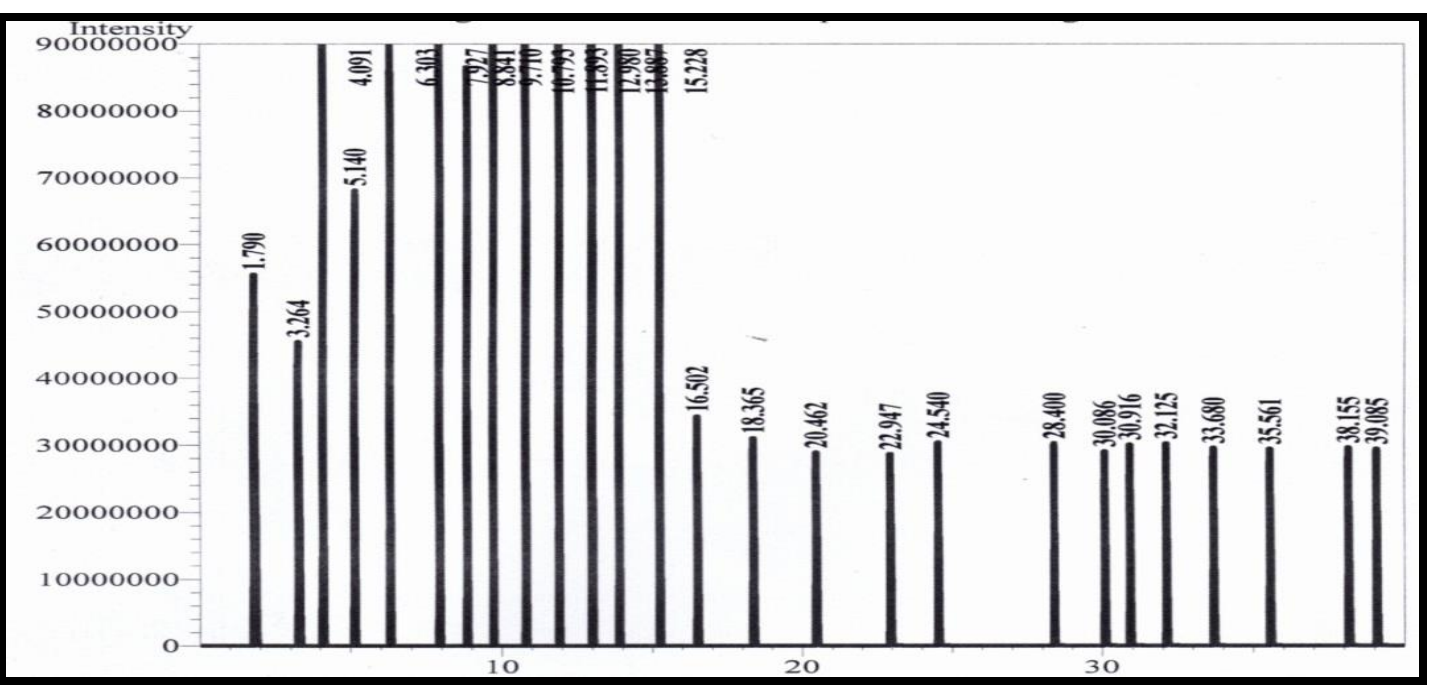

الثكل (3): الأحماض الدهنة في جزء الكليسيرايد الثلاثي

جدول (5): النسبة المئوية للأحماض الدهنية في جزء الدهون الفوسفاتية لمصل الام 


\begin{tabular}{|c|c|c|c|}
\hline صيام 30 يوما & نماذج السيطرة & \multirow{3}{*}{ الأحماض الدهنية } & \\
\hline \multicolumn{2}{|c|}{ العدد } & & \\
\hline 7 & 7 & & \\
\hline $1.50 \pm 4.31$ & $0.16 \pm 1.04$ & $6: 0$ & \multirow{13}{*}{$\sqrt{\mathscr{S}}$} \\
\hline $1.47 \pm 4.32$ & $0.17 \pm 1.92$ & 11:0 & \\
\hline $1.23 \pm 4.73$ & $0.14 \pm 2.14$ & $12: 0$ & \\
\hline $1.13 \pm 3.76$ & $0.15 \pm 2.34$ & $14: 0$ & \\
\hline $1.62 \pm 5.04$ & $0.09 \pm 2.25$ & $15: 0$ & \\
\hline $5.59 \pm 9.40$ & $0.22 \pm 2.11$ & $16: 0$ & \\
\hline $2.52 \pm 4.57$ & $0.23 \pm 2.14$ & 18:0 & \\
\hline $0.45 \pm 2.30$ & $0.29 \pm 2.61$ & $20: 0$ & \\
\hline $1.61 \pm 3.39$ & $0.16 \pm 2.63$ & $21: 0$ & \\
\hline $0.65 \pm 1.86$ & $0.24 \pm 1.84$ & $22: 0$ & \\
\hline $1.70 \pm 3.83$ & $0.17 \pm 2.50$ & $23: 0$ & \\
\hline $0.67 \pm 2.24$ & $0.22 \pm 2.63$ & $24: 0$ & \\
\hline $20.14 \pm 49.75$ & $2.24 \pm 26.15$ & المجموع الكلي (Total) & \\
\hline $0.80 \pm 2.06$ & $0.24 \pm 2.54$ & $18: 1$ trans & \multirow{5}{*}{$\underset{\Sigma}{s}$} \\
\hline $0.70 \pm 1.90$ & $0.21 \pm 2.53$ & 18:1cis & \\
\hline $0.44 \pm 2.38$ & $0.22 \pm 2.81$ & $22: 1$ & \\
\hline $0.67 \pm 2.81$ & $0.15 \pm 2.37$ & $24: 1$ & \\
\hline $2.61 \pm 9.15$ & $0.82 \pm 10.25$ & المجموع الكلي (Total) & \\
\hline $0.40 \pm 2.26$ & $0.18 \pm 2.52$ & $18: 2 \mathrm{n} 6$ & \multirow{6}{*}{$\underset{2}{\mathbb{S}}$} \\
\hline $0.75 \pm 1.80$ & $0.23 \pm 2.48$ & $18: 3 \mathrm{n} 6$ & \\
\hline $0.36 \pm 1.85$ & $0.29 \pm 2.61$ & $20: 4$ n6 & \\
\hline $1.64 \pm 4.06$ & $0.29 \pm 2.03$ & $22: 2 \mathrm{n} 6$ & \\
\hline $0.82 \pm 1.62$ & $0.34 \pm 2.57$ & $20: 5 \mathrm{n} 3$ & \\
\hline $3.97 \pm 11.59$ & $1.33 \pm 12.21$ & المجموع الكلي (Total) & \\
\hline
\end{tabular}

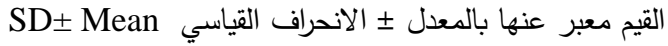

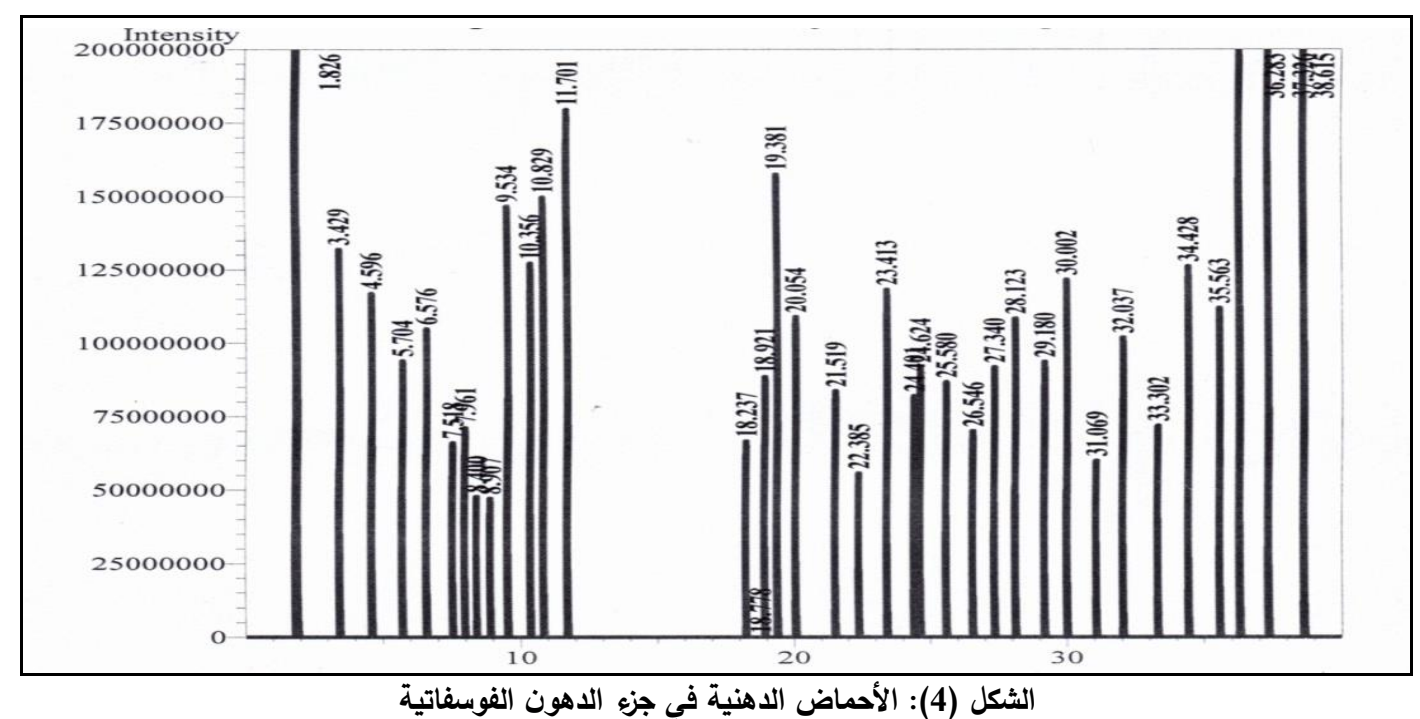

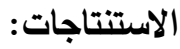

1. اشارت نتائج الدراسة الى وجود انخفاض معنوي في مستوى الكوليسترول الكلي في مصل الدم لمجموعة

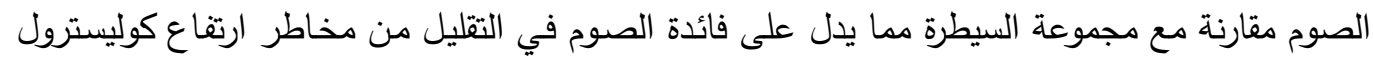

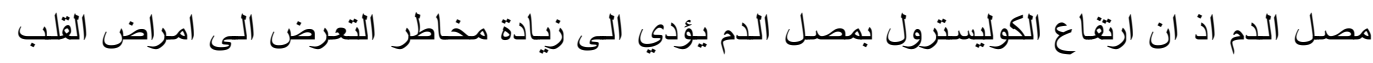
وتصلب الشرايين. 
2. اشـارت نتائج الدراسة الى وجود ارتفاع معنوي في مستوى HDL وانخفاض معنوي في مستوى LDL

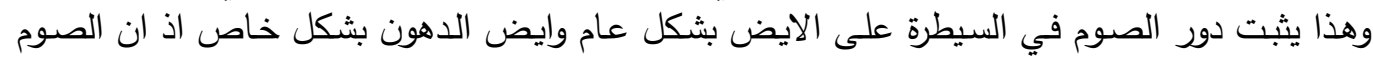

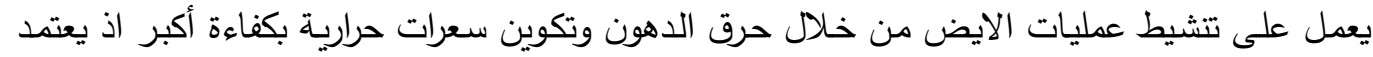

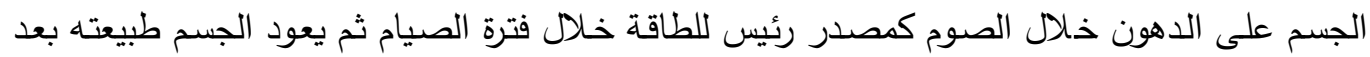

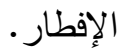

3. اشـارت نتائج الدراسة الى وجود تأثير الصوم على مستوى الاحماض الدهنية بأصنافها الثلاثة المشبعة

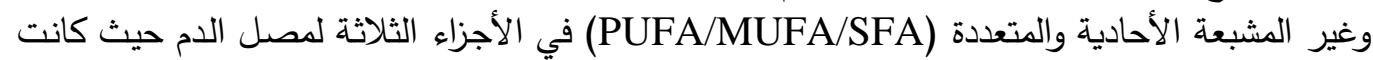

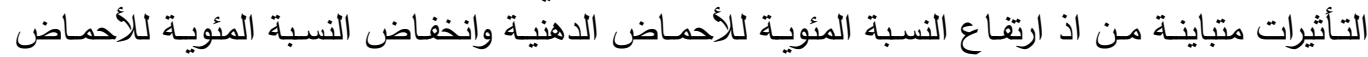

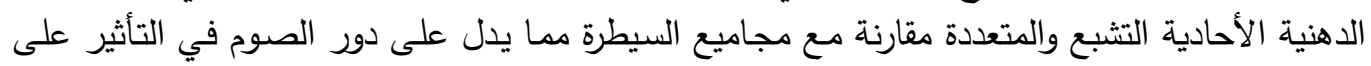

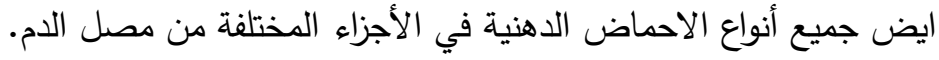

المصادر

1) Chtourou H., "Effects of Ramadan Fasting on Health and Athletic Performance" OMICS Group eBooks, USA; 3-6(2013).

2) Rehman J. and Shafiq M., JAMC., 12(3):13-15(2000).

3) Saedeghi H., Fauzee M.S.O., Jahromi M.K. and et al., Annals of Biological Research.,3(8):3958-3961(2012).

4) Elnasri H. A. and Ahmed A. M.,Sudanese Journal of Public Health., 1(3):203206(2006).

5) Junior A.M.C., Journal of Nutrition and Dietetics, 1(1):102(2017).

6) Fararjeh M.A., Aljamal A., Faris M.E. and et al.,Universal Journal of Medicine and Dentistry, 1(1):005-009 (2012).

7) Barkia A., Mohamed K., Smaoui M. and et al., J.Health popul.Nutr., 29(5):486493(2011).

8) Saleh S.A., Elsharouni S.A., Cherian B. and Mourou M., Mal Nutr., 11(2):143150(2005).

9) Ma J., Folsom A.R., Shahar E. and Eckfldt J.H., Am. J. Clin. Nutr., 62: 564571(1995).

10) Dasgupta A. and Wahed A., "Clinical chemistry, immunology and laboratory quality control". Elsevier Inc.,UK.,: 88-89, 8-9 (2014).

11) Leonard J.T and Kathleen R.L. "The Ways and Means of Statistics". Harcourt Brace Jovanovich,Inc.,USA.,:490-495 (1979).

12) Larijani B., Zahedi F., Sanjari M. and et al., Med.J. Malaysia,58(5)(2003).

13) Gnanou J.V., Caszo B.A., Khalil K.M. and et al., Journal of Diabetes and Metabolic Disorders, 14:55(2015).

14) Kamal S., Ahmad Q.S., Sayedda K. and UlHaque M., National Journal of medical research,2(4):407-410(2012).

15) Khan N., Rasheed A., Ahmed H., Aslam F. and Kanwal F.,Eastern Mediterranean Health Journal La Revue de Santé de la Mediterranee Orientale, 23(4): 274-279 (2017).

16) Fernandez M.L. and Webb D., Journal of the American College,27(1):1-5(2008).

17) Pinto X. and Ros E.,Clin Invest Arterioscl.,12:267-284(2000).

18) Genest J. Jr., Marcil M., Denis M. and Yu L., J Investig Med.,:47:31-42 (1999).

19) Miller M., Cannon CP., Murphy SA., Qin J., Ray KK. and Braunwald E.,J Am Coll Cardiol.,51 (7):724-730(2008).

20) Murray R.K., Gramner D.k. and Rodweu V.W., "Harper's Biochemistry". $25^{\text {th }}$ ed., Appleton and Lange, USA(2000).

21) Sauvat A., Chen G., Muller K. and et al., EBioMedicine, (2018).

22) Sabin M.A., Hora M., Holly J.M.P. and et al., Official Journal of the American academy of pediatrics, (2014).

23) Marks K.A., Marvyn P.M., Henao J.J.A. and et al., Genes Nutr., (2015).

24) Salo P., Vilkari J. and Routi T., Acta. Paediat., 89:399-405 (2000).

25) Nigam A., Smith N.F., Lesperance F. and Julien P., Nutrition, Metabolism and cardiovascular Diseases ,19: 264-270(2009).

26) Vessby B., Aro A. and Salminen., Am. Pia. Ass., 43:1353-1357 (1994).

27) Cardona J.B. and Rodriguez V.C., Nutrients, 8:54(2016).

28) Innis S.M., American Society for Nutrition. Adv. Nutr., 2:275-283 (2011). 